\title{
Study cognitive function in the elderly by testing rapid assessment of cognitive functions (ERFC)
}

\begin{abstract}
The prevalence of mild cognitive impairment (MCI), according to epidemiological and longitudinal studies are between 3 and $42 \%$, depending on diagnostic criteria used. The incidence stands at 8-58 per 1000 per year being higher in men. With an incidence of $1 \%$ per year in people over 70 years. From this we consider it necessary to conduct a thorough assessment, with measurement scales scientifically accepted to know what the current state of cognitive function of older adults, and in case of deterioration, to have evidence diagnoses that lead us to consider the correctly diagnosed it as a clinical pathology. That is why in our study we consider making an assessment of these cognitive functions in older adults, and then be able to draw conclusions from them.
\end{abstract}

Objective: Assess cognitive function in older adults.

Methodology:

Design: To meet the objectives of Probabilistic made a cross observational study.

Scope of the study: The study setting was ten centers belonging to His Major. City of Salamanca, participating in the Occupational Therapy Program.

Results: total study sample was 147 individuals. Mean age of the sample was 75.35 years ( \pm 6.707$) .82 .3 \%$ of the sample were women ( 121 women and 26 men). $78.9 \%$ had primary education, secondary education $10.2 \%$ and $10.9 \%$ had higher education. As for the results obtained in the ERFC, the mean total score was $49.62( \pm 4.26), 51$ being the cutoff point scientifically established to discuss mild cognitive impairment. Significant relationship between education and ERFC Total Score $(\mathrm{r}=0.188 \mathrm{p}<0.05)$, where a higher level of education improved cognitive function.

Conclusion: There is a deterioration of cognitive functions in older adults.

Keywords: cognitive functions, occupational therapy, seniors, mild cognitive impairment.

\author{
Volume 4 Issue 4 - 2019
}

\section{Eduardo josé fernández rodríguez, Celia} sánchez Gómez

Occupational therapist, School of Nursing and Physiotherapy, University of Salamanca, Spain

Correspondence: Eduardo josé fernández rodríguez, Occupational therapist, School of Nursing and Physiotherapy, Cancer Area Researcher. Institute of Biomedical Research of Salamanca, University of Salamanca, Spain, Email edujfr@usal.es

Received: July 24, 2019| Published: August 02, 2019

\section{Introduction}

In recent years, thanks to advances in both diagnostic medical techniques as therapeutic and pharmacological, life expectancy in Western society has been rising in January. ${ }^{1}$

WHO 2 indicates that the world population is aging rapidly. The world population over 60 will double between 2000 and 2050, as it will increase from approximately $11 \%$ to $22 \%$. Increasing in this period from 605 million to 2 billion people age or over 60 years. The number of elderly equal to or greater than 80 years, not double, but quadruple. There will in the world about 400 million people with equal or older than 80 years in 2050 , representing $20 \%$ of older adults. ${ }^{2}$

What is a fact is that scientific and medical advances have led to increased life expectancy, reducing mortality. This decrease in mortality has been accompanied by a declining birth rate, which is the passage of populations of high mortality and low birth populations of birth and death. It is important to note that this fact is responsible for important health, sociological and economic changes.

This population phenomenon began to study more than a decade. However, as then pointed to a study by the European Union, ${ }^{3}$ the main problems in older adults were economic hardship and loneliness, with the health problems which ranked third. However, the health costs of this sector of the population is a growing concern for society, consuming much of the public health resources of many healings.
What is clear is that the increase in life expectancy has increased the prevalence of neurodegenerative diseases,${ }^{4,5}$ with cognitive decline and dementia which is one of the most important problems of public health in developed countries, by high costs of treatment. It is for this reason that the study of cognitive function in older adults is currently booming.

The existence of these diseases and an increasing proliferation thereof, linked to the process of aging, which are of great significance from the point of biological, social, psychological and economic, force a restructuring of health resources and of course, social to meet this relatively new series of pathologies.

Given the large number of older adults, the study of cognitive functions is gaining great importance, ${ }^{5}$ among other reasons, as noted above, due to the decrease in mortality and longevity of people. ${ }^{6}$ Neuroscience offers techniques of structural and functional neuroimaging for observing the nervous system in operation, and provide increasingly reliable diagnostic mechanisms operating both healthy nervous system and pathologies that affect both the acute character as progressive and degenerative nature; and drug developments are providing better targeted treatments in specific symptoms, and less side effect burden.

All these advances have managed to increase the life expectancy and therefore, the longevity of the population has led to a progressive 
increase in the incidence and prevalence of degenerative diseases such as mild cognitive impairment (MCI) and dementia ${ }^{4}$ associated with that aging. The existence of these diseases and an increasing proliferation thereof, linked to the process of aging, which are of great significance from the point of biological, social, psychological and economic, force a restructuring of health resources and, of course, social to meet this relatively new series of pathologies.

Given the large number of older adults, the study of cognitive functions is gaining great importance, ${ }^{5}$ among other reasons, as noted above, due to the decrease in mortality and longevity of people. ${ }^{6}$

Generally, dementias are diseases that arouse greater clinicalhealth concern. However, there is a group of elderly population with undiagnosed cognitive impairment; since the DCL remains still underdiagnosed underrated. Thus, it becomes a risk population group. It is of great importance early diagnosis and subsequent intervention in this group of older adults.

All these changes in the process of aging produce various alterations in older adults, directly affecting their personal autonomy. Some changes are specific to age and others are produced by pathology. Both influence functional, cognitive, emotional and social level, limiting the normal course of their daily activities and self-perception of worsening their quality of life. For older adults, these parameters of quality of life can be influenced by the performance of rehabilitative techniques from the perspective of occupational therapy.

There are different concepts in scientific literature that try to define what we call aging. One of the most accepted concepts is considering aging as the set of morphological, functional and psychological changes, which over time brings irreversibly in living organisms.

From a biological perspective it is very difficult to define what is aging. For some is a genetic result; for other aging itself does not exist but is the consequence of the wear body. ${ }^{8}$ Whatever the cause, it is a fact that the physical and cognitive abilities decline with aging. Even in the case of healthy aging, with absence of pathology.

However, the set of changes that appear in the aging process, do not joint and suddenly for the sake of attaining a certain age. Just as they did not present the same in all individuals. In fact, this individual variability depends on numerous factors and conditions that may affect the health of the elderly.

We must begin to understand old age as another phase of our life cycle, like other stages such as childhood, adolescence or adulthood. It has its own characteristics, which will be introduced progressively, depending on individual intrinsic factors, personal attitudes and circumstances surrounding our lives.

According Juan Florencio Macias et al . ${ }^{9}$ in an effort to describe the physiological aging consider that "aging is an intrinsic, progressive, universal, downward, asynchronous process physiologically characterized by decreased functional performance which entails delay, difficulty and sometimes inability to adapt to adverse both biological situations such as psychological, social or environmental motivated by the passage of time and that failure to remedy in time, lead irreversibly to a situation of fragility, dependency and, ultimately, to death of the person" Today, we know that is not the chronological age, but biological and clinical status of each person should be noted that the barrier between the adult and the elderly. Fleeing the concept that, from a certain age, usually 65 or after the change of employment status to active a person is elderly retired. Consequently, we must begin to think that improved living conditions makes people reaching age 65 do so in a physical, mental and independence conditions which do not correspond to the stereotype and the concept that had "old". ${ }^{9}$ To define the concept of old age, from the chronological point of view, tend increasingly to consider the expectations of future life, Cognition, ${ }^{10,11}$ is a complex and dynamic system of interconnected components that allow us to organize and use information to be functional in the environment in which we live. The new information entering the system is organized and classified and already stored is evoked to interpret the new processing. Efferent response can be an action or movement, decision making or simply storing information for future use.

We can say that cognition is the ability to process information from perception, the knowledge we have gained through experience and our own individual characteristics that allow us to integrate the information received and thus be able to interpret the world around us. ${ }^{12}$

Cognition includes various cognitive functions. These basic cognitive functions are the result of the overall functioning of perception, attention, memory, visuospatial skill, orientation, reasoning, language and numeracy, some of which may be affected during the aging process: ${ }^{13,14}$ That is why so all these areas of cognitive functioning are subject to evaluation and intervention in older adults, when some deterioration of these or risk it is observed. These cognitive functions allow us to perform any task. And that is why, that enable the subject to have an active role in the process of receiving, sorting, processing, storage, processing and retrieval of information, which allows him to function independently in the world around him.

Improvements in health care which we currently enjoy, together with advances in science and research, have contributed to increase the longevity of people and as a result, the aging of the population. Inevitably this fact has led to increased prevalence of MCI and dementia.

However, there is considerable controversy as to the differentiation between normal cognitive aging and memory loss associated with age; between it and the DCL; and even more in terms of diagnoses $\mathrm{MCI}$ and the early stages of dementia criteria.

First, as discussed in the section, some authors and studies considered "normal" or something associated with advanced age, impaired memory and, on the other hand, other studies have tried to show that it is a mistake presupposing as a normal phenomenon cognitive impairment and more specifically memory impairment.

Second, in recent decades it is studying and trying to identify the cognitive, biological and behavioral changes that occur during the call presymptomatic stage of dementia, which is the DCL and during dementia itself.

In a review article,$^{15}$ try to draw conclusions to answer the question of whether the $\mathrm{MCI}$ is the state where ends normal aging and dementia begins. There are studies that suggest that there is no fixed event determine the starting point of the asymptomatic phase to the symptomatic phase of the pre-dementia, ${ }^{16}$ or symptomatic onset of dementia at pre-dementia stage. ${ }^{17}$

As already indicated, early diagnosis and incidence of MCI or dementia in the elderly is an issue that currently worries experts and researchers. There are works ${ }^{18}$ aimed at studying the factors in the elderly may come to influence the process of enjoying a normal and 
successful aging or conversely in developing impaired cognitive functions.

What is clear is that, to define the cognitive decline associated with older adults should be clear before the concept of normal cognitive aging.

But the concept of normality is often confusing, particularly in the context of aging. The confusion arises when normal as it is, "standard", "usual" is defined; or what is "not abnormal". ${ }^{19}$ The findings in the field of gerontological research emphasize the gap between what has been described as usual and abnormal in relation to aging. ${ }^{20}$ Although great strides have been made to distinguish disease (abnormal) in the last stage of life, what is normal in the aging process, progress has been less when defining what is usual. On the other hand, there is a tendency to expect a functional decline during aging in any parameter that is considered, which increases further confusion. This kind of expectations any aspect distorts normal elderly brain. Therefore, it is typical that emphasizes what has deteriorated, while selectively ignoring everything that has been strengthened over the years. This reflection illustrates the usefulness of defining Colarusso and Nemiroff, ${ }^{21}$ which is considered normal in a changing biopsicosocial context is the aging process.

As noted, the opinions about what is "normal" or not about cognitive aging process are very divided. On the one hand, some authors ${ }^{22}$ consider that there is a decline in terms of speed of information processing, and memory and even verbal fluency; greater or lesser extent, but says it is something associated with senescence. However, these studies indicate declines in cognitive functions as part of normal cognitive aging do not consider pathological data subjects, only psychometric data.

On the other hand, several studies, ${ }^{23-25}$ considering greater the presence or absence of brain pathological changes and against these claims, concluded that normal elder does not have to have a significant cognitive impairment, nor neuropathology. That is, the normal cognitive aging differs clearly cognitive aging in which the brain degeneration occurs, or not having pathology.

In the aging person without disease, neuronal loss is limited to discrete areas (coeruleos locus, substantia nigra, nucleus basalis of Meynert) and has individual variations, accompanied by an increase in glial cells, microglia unaffected. This discrete neuronal loss that accompanies aging contrasts with the large cell death listed on degenerative diseases of the central nervous system (CNS) such as Alzheimer's or Parkinson. ${ }^{26}$

Based on these latest statements, it would be a mistake to think that it is absolutely normal and part of the logical process that an older adult shows memory complaints or are observed in the cognitive impairment, and, on the other hand, do not think that is a warning signal as the beginning of a disease.

The importance and interest in early detection of dementia leads to various attempts to determine stages between normal cognitive aging and dementia. ${ }^{27,28}$ Have established a number of concepts about $\mathrm{MCI}$, considering it either as part of the aging process or as an early stage of dementia, often Alzheimer-type dementia (ATD) or Alzheimer's disease (AD) ${ }^{29}$ Some authors ${ }^{27}$ they have proposed that term as a clinical situation involving elderly people with cognitive and functional impairment.

Thus, attempts to identify those subjects with abnormal cognitive losses objective, beyond the characteristics of healthy older adults. ${ }^{30}$ MCI concept has evolved considerably over the past two decades and is still very popular in recent years. As individuals age, the quality of cognitive function becomes an increasingly important issue, which themselves are concerned considerably.

The MCI is currently the most widely used concept to refer to the state between normal aging and dementia. ${ }^{32-34}$ The fact defines the concept is important for healthcare professionals are aware of the condition and locate in the appropriate clinical setting. ${ }^{34}$

This concept was proposed by the team at the Mayo Clinic and at the end of the $90 \mathrm{~s} 62$, being the term most popular and widely used. It defined the MCI as cognitive impairment which exceeds the normally expected for age but not meeting criteria for dementia, because the functionality is preserved. ${ }^{36}$ ie, the MCI conceptually corresponds to subjective deficits and objectives of cognition, abnormal for age, but no compromises in the development of the subject AVD. Although this construct was initially defined by Flicker et al. ${ }^{37}$ based on the Global Deterioration Scale of Reisberg, Ferris, Leon \& Crook. ${ }^{38}$

Currently, there are studies ${ }^{39}$ that consider that, although there is no involvement of basic activities of daily living (ADL), there may be evidence of subtle deficits in the instrumental activities of daily living (IDL) in the MCI. Another more fully defined by Petersen and colleagues in $2003^{40}$ is as follows (Table 1):

Table I MCl definition by Petersen and colleagues in $2003^{7}$

\begin{tabular}{ll}
\hline & I. Subject not normal, not demented (the criteria for dementia, DSM-IV and ICD-I0) are not met. \\
& 2. Cognitive decline defined as: \\
$\begin{array}{l}\text { Deterioration } \\
\text { cognitive }\end{array}$ & Self-reporting or reporting and objective report deterioration in cognitive tasks. \\
mild & Evidence of decline over time on objective cognitive tasks.
\end{tabular}

3. Preserved basic activities of daily living (ADLs) and minimal deterioration in more complex instrumental activities (IADLs).

As defined by Petersen, the MCI is defined as a state between normal cognition and dementia, characterized by deficits that are not explainable by age, educational level, or medical illnesses. ${ }^{40}$

It is important to note that these classifications should not be used as diagnostic tools, but as tools to establish different degrees of deterioration or absence. ${ }^{41}$ The severity of this alone should not determine a specific diagnosis.
It is interesting by the fact that the classifications of diseases most commonly used, the International Classification of Diseases (ICD10) and the Diagnostic and Statistical Manual of Mental Disorders (DSM-IV), do not include MCI entity. However, Petersen et al. ${ }^{41}$ have proposed the inclusion of the term in the fifth edition of DSM.

There are several diagnostic criteria for MCI, although they all have in common that subjects with MCI have objectified cognitive 
impairment and the absence of dementia. On the one hand, are the criteria proposed by the Mayo Clinic that pertain only to amnesic subtype. And on the other hand, are the criteria of the International Psychogeriatric Association (IPA), which are proposed by Levy ${ }^{42}$ but with modifications.

However, numerous studies ${ }^{43}$ have shown the great breadth of the concept, including his subjects with a variety of deficits ${ }^{44}$ and with some involvement in the AVD more complex ${ }^{45}$ thus demonstrating the heterogeneity of the concept, both in clinical presentation and etiology. This motif has led researchers to question the criteria of MCI. Thus, the International Working Group of Mild Cognitive Impairment ${ }^{46}$ has proposed a series of recommendations on the general criteria. Stressing the importance of clinical evaluation, neuropsychological assessment, accompanied by an interview with the family/caregivers.

As the prevalence of MCI, epidemiological and longitudinal studies are between 3 and $42 \%$, depending on diagnostic criteria used. Following the criteria of the Mayo Clinic is $12-18 \%$ in people age or over 65 years. The incidence stands at $8-58$ per 1000 per year being higher in men. ${ }^{47}$ With an incidence of $1 \%$ per year in people over 70 years. ${ }^{48}$

However, these definitions we only approach the end, it is necessary to conduct a thorough assessment, with measurement scales scientifically accepted to know what the current state of cognitive function of older adults, and in case of deterioration, to have evidence diagnoses that lead us to consider the same as a correctly diagnosed clinical pathology.

That is why so in our study we propose to assess these cognitive functions in older adults, and then be able to draw conclusions from these.

\section{Main goal}

Assess cognitive function in older adults.

\section{Specific objectives}

i. Assess cognitive performance in older adults.

ii. Assess the impact of gender of older adults with cognitive function.

iii. Analyze the correlation between cognitive function of individuals and the age of these.

iv. Describe if the level of education influences the cognitive function of the subjects.

\section{Method}

Design: To meet the objectives of Probabilistic made a cross observational study.

Scope of the study: The study setting was ten centers belonging to His Major. City of Salamanca, participating in the Occupational Therapy Program.

\section{Selecting the sample}

\section{Study population}

The study healthy older adults of both sexes, noninstitutionalized participated, in the town of Salamanca who voluntarily conducted the Occupational Therapy Program, conducted by the University of Salamanca, in the Support Center for Seniors, during the years 20172018.
To participate in the Occupational Therapy Program annually in the period from May to June, the Council of Elders of the City of Salamanca proceeds to collect applications from the largest Associations of Elders of the town you wish to participate in the course following in the Occupational Therapy Program.

In cases where there are more applications than places available, it proceeds to the realization of a public drawing to award the square.

\section{Inclusion criteria}

1. Have an equal or older than 60 years and enroll voluntarily Occupational Therapy Program manner.

2. It is accepted in the Occupational Therapy Program.

3. Voluntarily authorize their participation in the study by signing an informed consent.

\section{Exclusion criteria}

1. Present clinically diagnosed cognitive impairment.

2. Not have numeric and literacy skills.

3. Not authorize their participation in the study.

4. Participate in some other cognitive stimulation program regularly.

\section{Sample size}

The study sample was formed by all users of the different centers more assigned to the Occupational Therapy Program offered by the University of Salamanca, who met the criteria for inclusion/exclusion, which authorized their participation in the study voluntarily by signing an informed consent.

\section{Description of a study variable}

\section{The study variables were:}

\section{Dependent variable}

Cognitive performance: Measurement with Rapid Assessment of cognitive functions (ERFC). The ERFC plus a total score will give us other variables: spatiotemporal orientation, attention and memory, mental arithmetic, reasoning and judgment, similarities, comprehension, naming, repetition, written order, verbal fluency, praxias, visual recognition and writing.

\section{Variables involved}

Age

Sex

Level studies

\section{Assessment and collection instruments results}

For the dependent variable, subjects will undergo the test ERFC. ERFC Test measures cognitive ability and enables rapid evaluation and early diagnosis of possible cognitive deficits. It is an adaptation Castilian Rapid Assessment test of cognitive functions (ERFC) Gil and his colleagues ${ }^{49}$ whose original version is French. This test was translated by Eva Maria Arroyo-Anlló and published in the book Handbook of Neuropsychology..$^{50,51}$

The original ERFC test consists of three items unless they were subsequently added in the Spanish version (ERFC.es), which is the version to be used for this project. 
Currently, the Spanish version of Test ERFC.es we use in our country consists of 13 subtests that measure cognitive functions following:

i. Spatiotemporal orientation: Which assesses orientation in space and time.

ii. Attention and memory: Which explores one hand, attention span, immediate memory and working memory; and on the other hand, I remember that examines the ability of long-term learning, unassisted or by induced memory, semantic indications of offering words unremembered freely.

iii. Mental calculation: Explored through two subtractions.

iv. Reasoning and judgment.

v. Similarities: Which assesses the ability of abstraction.

vi. Understanding: This evaluates oral comprehension.

vii. Denomination: Explored through the designation of two real objects and two images.

viii. Repetition.

ix. Written order: Which explores the written understanding.

$\mathrm{x}$. Verbal fluency: Examining one hand semantic creep and secondly alternating phonetic creep, which explores the capacity alternation and inhibition of verbal responses.

xi. Praxias: He is studying the intentional, symbolic gesture (praxia Ideomotor) and constructive praxia.

xii. Visual recognition: evaluating the visual gnosia.

xiii. Writing: explored through copying and dictation of two words.

The cutoff for ERFC, indicating a possible cognitive impairment is in 51 of 56 (with a sensitivity of 0.92 and specificity of 0.86 ) and 46 points over ${ }^{51}$ for the group of subject's illiterates (with a sensitivity of 0.9 and a specificity of 0.88 ).

For adaptation and validation of ERFC in Spanish a study ${ }^{52}$ was conducted with a sample of 369 older adults without a diagnosis of any pathology, aged 63 to 81 years; which would be the target population of this project. With the results the following psychometric properties established: The ERFC meets criteria test-retest reliability ( $\mathrm{r}=0.38)$, validity of content $(70 \%)$, according to test Morillama ${ }^{53}$ by agreement between judges construct validity $(\mathrm{MEC}=0.82$ and $\mathrm{ERFC}=0.9)$ and internal consistency (Cronbach's alpha $=0.8$ ). Had a sensitivity of $0.92 \%$ and a specificity of $0.86 \%$ with $51 / 56$ breakpoint. That is, as a conclusion we can say that the validity and reliability of ERFC is confirmed.

Variables involved: a registration document or medical history for each participant. was used a recording sheet containing personal data and filiation was designed, as well as educational level and senior center to which it belongs

Procedure: Upon request participate in the program of Occupational Therapy and be admitted, we proceeded to test whether subjects met inclusion criteria to participate in the study. Later, after obtaining informed consent signed by the subjects, we proceeded to the evaluation. On the one hand, the test Rapid Assessment of cognitive functions (ERFC) was used to measure cognitive function; and secondly, a specific recording sheet for collecting sociodemographic data (age, gender and cultural level) was designed.

\section{Statistical methods}

\section{Descriptive statistics}

Quantitative variables following a normal distribution are defined by mean and standard deviation.

For quantitative variables that do not follow this distribution, the median is used instead of the average as a measure of centralization.

To evaluate if the variables follow a normal distribution, the Kolmogorov-Smirnoff used.

Qualitative variables are defined by the number of cases and percentages.

\section{Statistical analytical}

To analyze quantitative variables will use the Pearson correlation coefficient.

Two qualitative variables to assess the statistical chi-square test was used.

For a qualitative variable ( 2 categories) and a quantitative variable, the statistical test is used STUDENT T.

To define a qualitative variable (more than two categories) and a quantitative variable, the ANOVA statistical test, whose graphical representation is performed by using diagrams.

\section{Data processing} 24.0

The process of data analysis was performed using SPSS version

\section{Results}

The total study sample was 147 individuals. The average age of the sample was 75.35 years $( \pm 6.707)$. As for the sex of participants, $82.3 \%$ of the sample were women (121 women and 26 men). Respect to educational attainment, $78.9 \%$ had primary education, secondary education $10.2 \%$ and $10.9 \%$ had higher education. The demographic characteristics of the participants are summarized in Table 2.

Table 2 Sociodemographic characteristics of the sample

\begin{tabular}{lllllll} 
Sex & & Age & \multicolumn{4}{l}{ Education Level } \\
N & & Half & $\mathrm{S}$ & primary & $\mathrm{N}=116$ & $78.9 \%$ \\
Male & 121 & 75.35 & 6,707 & secondary & $\mathrm{N}=15$ & $10.2 \%$ \\
Woman & 26 & & & higher & $\mathrm{N}=16$ & $10,9 \%$
\end{tabular}

As for the results obtained in the ERFC, the mean total score was $49.62( \pm 4.26),{ }^{51}$ being the cutoff point scientifically established to discuss mild cognitive impairment. As for the different cognitive functions that evaluates the ERFC, items in which we see further deterioration are attention, immediate memory and working memory and reasoning. By contrast, the items were less deterioration is observed, or none are writing and the written order. Descriptive statistics are shown in detail in Table 3.

As for the relationship between the scores in ERFC and different demographic variables, one can say that there is a significant relationship between education and ERFC Total Score ( $r=0.188 \mathrm{p}$ $<0.05$ ), where higher level of education better cognitive function. In addition, we can see that the older of individuals underscores obtained in the ERFC. As for the sex of individuals there is no difference in cognitive function. Data more thoroughly, we can be found in Table 4. 
Table 3 Descriptive statistics of the study variables

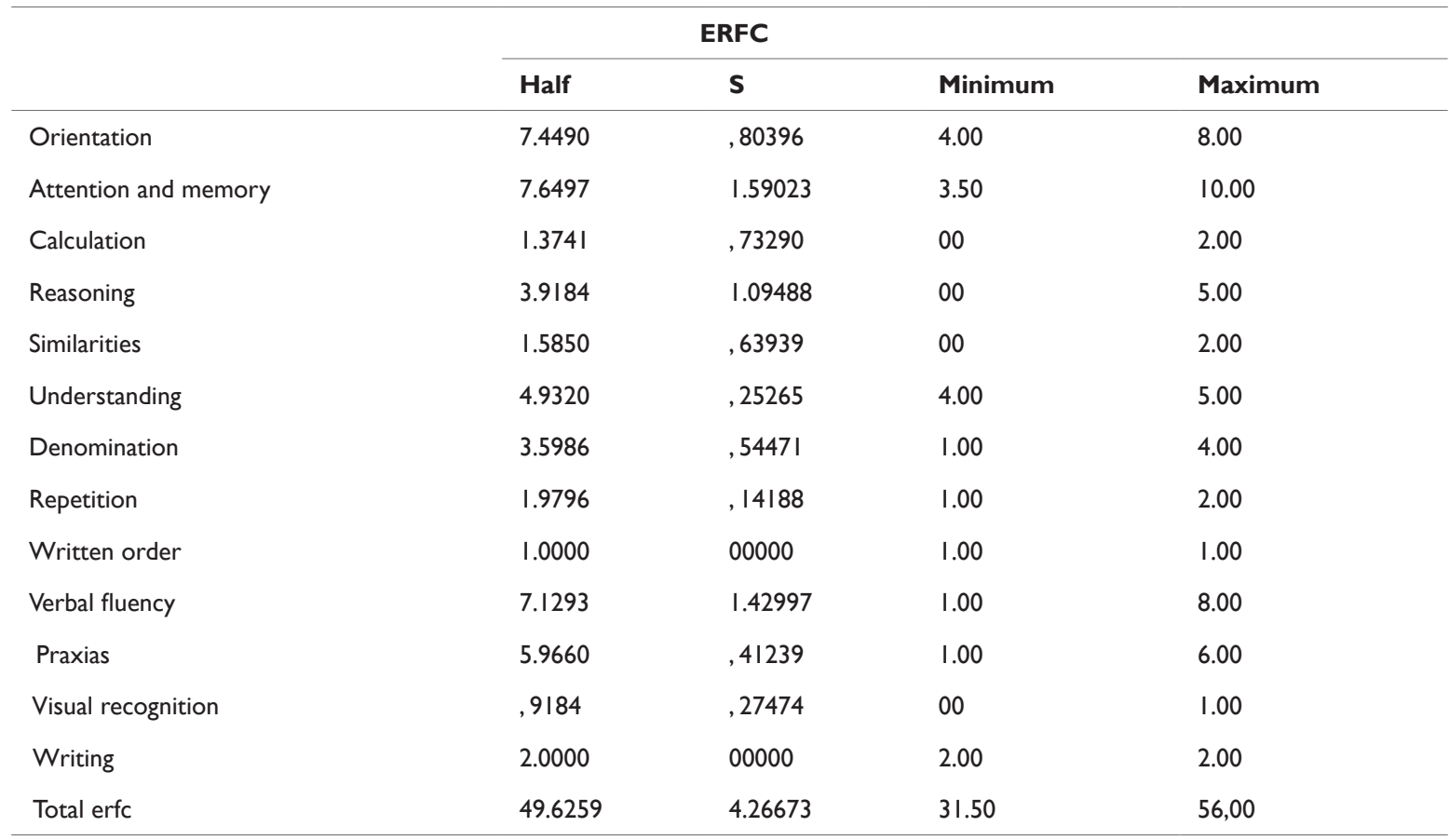

Table 4 Study of correlations between the different variables under study

\begin{tabular}{llllll}
\hline & & Cultural level & Total erfc & Age & Sex \\
\hline Education level & Pearson correlation & $\mathrm{I}$ & $188 *$ &,- 093 &,- 019 \\
& Sig. (Bilateral) & & 22 & 262 &, 823 \\
& $\mathrm{~N}$ & 147 & 147 & 147 & 147 \\
Total erfc & Pearson correlation & $188 *$ & one &,- 093 & -114 \\
& Sig. (Bilateral) & 22 & & 264 & 169 \\
& $\mathrm{~N}$ & 147 & 147 & 147 & 147 \\
Age & Pearson correlation &,- 093 &,- 093 & one & 13 \\
& Sig. (Bilateral) & 262 & 264 & &, 872 \\
\hline
\end{tabular}

\section{Discussion}

Conducting this research arose from the need to study the cognitive function of a population of noninstitutionalized older adults who participate in a program of Occupational Therapy, residing in the town of Salamanca. The results described show cognitive performance of older adults who participated in the study, analyzing their cognitive ability through ERFC and its relationship with different variables that could intervene in such cognitive performance.

Currently there is talk of increased life expectancy, but perhaps its importance is not only in the years of life, if not in the quality of life of older adults during that time. Therefore, we believe that the main obstacle to consider considering whether a longer life expectancy is worthy, it is autonomy; in the fact that the elderly maintains, as far as possible, independent to perform their daily activities. And that realization of these allows adapt to physiological changes of aging, as far as possible in their environment and community.

Consider cognition as a fundamental tool to promote the functionality of individuals in their ADLs, and although they can give significant declines associated with age in many cognitive abilities, we must strengthen that most older adults retain their ability to function effectively in their daily lives. How to capture the elderly to Occupational Therapy Program and therefore recruit for this research it is through the Department of Aging of the City of Salamanca, which is responsible for promoting participation among the different associations and municipal senior centers in the program. Therefore, we can say that we have a convenience sample, as in most of the revised jobs, ${ }^{54-56}$ since the samples resulting from the voluntary registration and those subjects who subsequently They have met all the inclusion criteria and presented no exclusion criteria.

The final study sample was composed of $17.70 \%$ men and $82.30 \%$ women; Noting that clearly predominantly female. This majority proportion of women is almost standard in the literature and analyzed. ${ }^{55,57-59}$ But from these results, we have to be aware that, taking into account the great difference between individuals of one sex and another, the results can be biased, so we prefer to talk about preliminary results. In addition to considering that this item must be studied further in future research to clarify it in the most timely manner. 
The sample had a mean age of 75.35 years $(s=6,707)$; reaching a similar parameter that are handled in different studies. ${ }^{55,56,58-60}$

As for the variable level of studies included in our study because of the large number of jobs. ${ }^{61,62}$ They are linking the high level of education with better cognitive capacity during aging, with increased cognitive reserve and neuroplasticity. And on the other hand, other studies $^{63,64}$ indicate that the low educational level may be related to factors that may increase the risk of cognitive impairment and dementia during life. They predominated in our sample primary education $(78.90 \%)$. This reflects how, in general, the education level of the elderly is low, prevail people with few years of schooling or no access to schooling, particularly the educated. This being a factor which, as discussed below, can influence cognitive performance of the elderly or be a protective factor against cognitive decline; and even influence, as some authors ${ }^{65}$ in the self-perception of health and in the presence of greater subjective complaints of memory. The results obtained in relation to the ERFC test showed a total score of $49.62( \pm 4.26)$. This score indicated the presence of a deterioration of cognitive functions in our sample of older adults; considering that the point $^{51}$ is cut.

Obtaining this data refers to all those authors who argue that there are now a significant number of older adults with cognitive impairment ${ }^{66}$ undiagnosed and therefore untreated. It is a fragile population with many risk factors (quality of life that begins to slow, repeated consultations, misguided treatments, lack of adherence to medication, difficulties in everyday life, etc.). For these reasons, it is essential to make an early diagnosis of cognitive impairment. The relevant health professionals are prepared for early detection, it will be important to try to reduce the economic, family and health services load, trying to prevent that MCI could evolve into dementia.

In that sense, the cognitive assessment is essential for the diagnosis of MCI, since it is the only way to detect subtle cognitive deficits that might go unnoticed. This assessment accompanying subsequently scales with functionality as well as laboratory tests and neuroimaging; to make a complete evaluation and a correct diagnosis.

Regarding cognitive functions that evaluates the ERFC, those where further deterioration was observed were attention, immediate memory, working memory and reasoning. Similar results are shown in other studies that indicate that during aging cognitive functions most affected, and more specifically the functions of the affected memory are working memory, ${ }^{66,67}$ episodic memory ${ }^{68,69}$ and prospective memory. ${ }^{67}$

In contrast, cognitive functions that decline was observed less or none were writing and the written order. Coinciding with other research, who argue that during Aging does not appear to significantly alter the language 28. But if we see that older adults tend to produce longer definitions, using explanations and descriptions of many words, compared to young. ${ }^{70,71}$ In addition to the findings indicated, our results inform us of the existence of a negative and statistically significant correlation between the age of seniors in our sample and cognitive performance (ERFC). That is, older of the elderly is correlated with lower scores on this scale and younger age correlated with higher scores.

López ÁG et al. in their study ${ }^{54}$ showed this negative correlation between age and cognitive performance of most adults. Considering age as a risk indicator or predictor of cognitive impairment. Menor
$\mathrm{J}$ et al. ${ }^{55}$ on a sample of 164 older adults with an average age of ${ }^{71.57}$ years obtained like those obtained in our research results, as proved the existence of a correlation between age and cognitive performance participants, like us with scores of ERFC.

The opposite is true educational level of individuals. With the results we can say that there is a positive and significant relationship between the level of education in our sample of older adults with cognitive performance (ERFC). It is indicating that the higher-level studies are higher scores on the scale ERFC. Menor $\mathrm{J}$ et al, ${ }^{55}$ are again like our results. Also getting a positive and significant between education level and cognitive performance in their sample of elderly correlation.

\section{Conclusion}

1. There is a deterioration of cognitive functions in older adults.

2. Older adults who have a higher level of education have suffered a minor alteration in overall cognitive function.

3. The increasing age in older adults is a further deterioration of cognitive functions.

\section{Funding}

None

\section{Acknowledgments}

None.

\section{Conflict of interests}

Authors declare that there is no conflict of interest

\section{References}

1. Muñoz J, Alix C, Muñoz T. Aging psychology and psychosocial intervention. Aging psychology. Madrid: Ediciones Pirámie. 2002:28.

2. http://www.who.int/features/factfiles/ageing/ageing_facts/es/

3. Department of economic and social affairs, population division. world population prospects: The 2015 revision, key findings and advance tables. United Nations, 2018.

4. Bermejo PF. Dementia of the elderly can be prevented. Rev Neurol. 2010;51:257-258.

5. Kales HC, Gitlin LN, Lyketsos CG. Assessment and management of behavioral and psychological symptoms of dementia. BMJ. 2015;350-369.

6. Custodio N, Montesinos R, Alarcón JO. Historical evolution of the concept and current criteria for the diagnosis of dementia. Rev Neuropsiquiatr. 2018;81(4):235-249.

7. Marín JM. Aging. Salud Pública Educ Salud. 2003;3(1):28-33.

8. Bermejo FP. Biological theories of aging. Rev Gerontol. 1993.

9. Álvarez J, Macías JF. Dependence on geriatrics. Salamanca: University of Salamanca editions; 2009.

10. Orueta UD, Febrero MBM, Pereiro JMM. Memory gymnastics: a cognitive stimulation program for the elderly based on objectives. Universidad de Deusto; 2010.

11. Grieve J, Gnanasekaran L. Introduction to evaluation. IN: Grieve J, editor. Neuropsychology for occupational therapists: evaluation of perception and cognition. 2nd ed. Madrid: Editorial Médica Panamericana; 2000:91-99. 
12. Grieve J, Gnanasekaran L. Neuropsychology for occupational therapists. Cognition in occupational performance. 3rd ed. Madrid: Médica Panamericana; 2009.

13. Cancino M, Rehbein FL, Ortiz MS. Cognitive functioning in older adults role of cognitive reserve, social support and depression. Rev Med Chile. 2018;146(3):315-322.

14. Luo L, Craik F. Aging and memory: a cognitive approach. Can J Psychiatry. 2008;53:346-353.

15. Custodio N, Herrera E, Lira D, et al. Mild cognitive impairment: where does normal aging end and dementia begin?. An Fac med. 2012;73(4):321330 .

16. Sperling R, Aisen P, Beckett L, et al. Towards defining the preclinical stages of Alzheimer's disease: recommendations from the National Institute on Aging-Alzheimer's Association workgroups on diagnostic guidelines for Alzheimer's disease. Alzheimers Dement. 2011;7:280-292.

17. McKhann G, Knopman D, Chertkow H, et al. The diagnosis of dementia due to Alzheimer's disease: recommendations from the National Institute on Aging-Alzheimer's Association workgroups on diagnostic guidelines for Alzheimer's disease. Alzheimers Dement. 2011;7:263-269.

18. Lorenzo J, Fontán L. The boundaries between normal cognitive aging and Alzheimer's disease. The concept of mild cognitive impairment. Rev Med Uruguay. 2003;19(1):4-13.

19. Bosch RI, Zayas T, Hernández E. Algunos determinantes sociales y su impacto en las demencias. Rev Cub Salud Pública. 2017;43:449-460.

20. Winblad B, Amouyel P, Andrieu S, et al. Defeating Alzheimer's disease and other dementias: a priority for European science and society. Lance Neurol. 2016;15(5):455-532.

21. Colarusso CA, Nemiroff RA. Clinical implications of adult developmental theory. Am J Psychiatry. 1987

22. Calero MD, Navarro E. Variables que favorecen un envejecimiento exitoso Estud Psicolog. 2018;39(2):215-24.

23. Lezak M. Neuropsychological Assesment. 4th ed. New York: Oxford University Press; 1999:288.

24. Riley KP, Snowdon DA. The challenges and successes of aging: Findings from the Nun Study. Adv Med Psychother. 2000; 10:1-12.

25. Snowdon DA. Aging and Alzheimer's disease: lessons from the Nun Study. Gerontologist. 1997;37(2):150-156.

26. Torres M. Aging physiology. In: Guillén F, Pérez del Molino J, editores Syndromes and care in the geriatric patient. Barcelona: Elsevier Masson. 2008;31-45

27. Petersen RC, Smith GE, Waring SC, et al. Mild cognitive impairment: Clinical characterization and outcome. Arch Neurol. 1999;56(3):303-308.

28. Petersen R, Stevens J, Ganguli M, et al. Practice parameter: early detection of dementia: mild cognitive impairment (an evidence-based review). report of the quality standards subcommittee of the american academy of neurology. Neurology. 2001;56:1133-11342.

29. Donaghy PC, Taylor J, T O’Brien J, et al. Neuropsychiatric symptoms and cognitive profile in mild cognitive impairment with Lewy bodies. Psychol Med. 2018;48(14):2384-2390.

30. Jiménez MA, Guerrero JLG. Patología asociada al deterioro cognitivo leve. Factores de riesgo y predictivos. Rev Esp Geriatr Gerontol. 2017;52:20 23.

31. Valls-Pedret C, Molinuevo JL, Rami L. Early diagnosis of Alzheimer' disease: prodromal and preclinical phase. Rev Neurol. 2010;51:471-480.
32. Mulet B, Sánchez-Casas R, Arrufat MT, et al. Deterioro cognitivo ligero anterior a la enfermedad de Alzheimer: tipologías y evolución. Psicothema. $2005 ; 17(2): 250-256$

33. Seshadri S, Beiser A, Au R, et al. Operationalizing diagnostic criteria for Alzheimer's disease and other age-related cognitive impairment-Part 2. Alzheimers Dement. 2011;7(1):35-52.

34. Petersen RC. Mild cognitive impairment. Continuum (Minneap Minn). 2016;22(2):404-418.

35. Petersen RC, Smith GE, Waring SC, et al. Aging, memory, and mild cognitive impairment. Int Psychogeriatr. 1997;9(1):65-69.

36. Petersen R. Conceptual overview. In: mild cognitive impairment: aging to alzheimer's disease, 1st ed, New York: Oxford University Press; 2003:114

37. Flicker C, Ferris SH, Reisberg B. Mild cognitive impairment in the elderly: predictors of dementia. Neurology. 1991;41(7):1006-1009.

38. Reisberg B, Ferris SH, de Leon MJ, Crook T. The Global Deterioration Scale for assessment of primary degenerative dementia. Am J Psychiatry. 1982; 139(9):1136-1139.

39. Jekel K, Damian M, Wattmo C, Hausner L, et al. Mild cognitive impairment and deficits in instrumental activities of daily living: a systematic review. Alzheimers Res Ther. 2015;7(1):17.

40. Petersen RC. Mild cognitive impairment clinical trials. Nat Rev Drug Discov. 2003;2:646-653.

41. Gauthier S, Reisberg B, Zaudig M, et al. Mild cognitive impairment. Lancet. 2006;367(9518):1262-1270.

42. Levy R. Aging-associated cognitive decline. working party of the international psychogeriatric association in collaboration with the world health organization. Int Psychogeriatr. 1994;6:63-68.

43. Cancino M, Rehbein L. Anticipatory signs and risk factors for mild cognitive impairment (MCI): A synoptic view. Ter Psicol. 2016;34(3):183189

44. Donaghy PC, Taylor J, T O'Brien J, et al. Neuropsychiatric symptoms and cognitive profile in mild cognitive impairment with Lewy bodies. Psychol Med. 2018;48(14):2384-2390.

45. Griffith HR, Belue K, Sicola A, et al. Impaired financial abilities in mild cognitive impairment: a direct assessment approach. Neurology. 2003;60(3):449-457.

46. Sánchez JL, Calvo JI, Sánchez JL. Effects of moderate physical exercise on cognition in adults over 60. Rev Neurol. 2018;66(7):230-236.

47. Caracciolo B, Palmer K, Monastero R, et al. Occurrence of cognitive impairment and dementia in the community: a 9-year-long prospective study. Neurology. 2008;70(2):1778-1785.

48. Larrieu S, Letenneur L, Orgogozo JM, et al. Incidence and outcome of mild cognitive impairment in a population-based prospective cohort. Neurology. 2002;59(10):1594-1599.

49. Gil R, Toullat G, Pluchon C, et al. Une methode d'evaluation rapide des fonctions cognitives (ERFC). Son application a la demence senile de type Alzheimer. Sem Hop Paris. 1986;62:2127-2133.

50. Gil R. Neuropsychology Manual. Barcelona: Masson; 1999.

51. Gil R. Manual of Neuropsychology, 2nd edn. Barcelona: Masson; 2006

52. Arroyo EM, Chamorro J, Castañeda C, et al. Adaptación y validación del test Evaluación Rápida de las Funciones Cognitivas (Gil et al, 1986). Primera versión en castellano con una muestra geriátrica. Psiq Biol. 2009;16(3):112-121. 
53. Morillama IM. Indicator of social changes. Problems in the measurements of health status. New York: Rusel Sage Foundation; 1968.

54. Labra JA, Menor J. Daily stimulation and cognitive functioning: the importance of the participation of healthy older people in cognitively demanding daily activities. EJIHPE. 2015;4(3):309-319.

55. Menor J, Labra JA, Albuerne F. Cognitive aging and Instrumental Activities of Daily Life: development of a dependency assessment instrument. Madrid: Fundación MAPFRE. 2008.

56. Velilla LM, Soto E, Pineda D. Efectos de un programa de estimulación cognitiva en la memoria operativa de pacientes con deterioro cognitivo leve amnésico. Rev Chil Neuropsicol. 2010;5(3):185-198.

57. García J, Fernández PJ, Fuentes LJ, et al. Differential effectiveness for two memory training programs in older adults with subjective memory complaints (mnemonic training vs. everyday forgetfulness training): an exploratory analysis. An Psicol. 2014;30(1):337-45.

58. Zamarrón MD, Tárraga L, Fernández R. Cognitive plasticity in people with Alzheimer's disease who receive cognitive stimulation programs. Psicothema. 2008;20(3):432-437.

59. Garamendi F, Delgado DA, Amaya MA. Cognitive training program in older adults. Rev Mex Med Fís y Rehab. 2010;22(1):26-31.

60. Thomas KR, Marsiske M. Verbal prompting to improve everyday cognition in MCI and unimpaired older adults. Neuropsychology. 2014;28(1):123134

61. Le Carret N, Lafont S, Mayo W, et al. The effect of education on cognitive performances and its implication for the constitution of the cognitive reserve. Dev Neuropsychol. 2003;23(3):317-337.

62. Bennett DA, Schneider JA, Wilson RS, et al. Education modifies the association of amyloid but not tangles with cognitive function. Neurology. 2005;65(6):953-955.
63. Wang H, Gustafson DR, Kivipelto M, et al. Education halves the risk of dementia due to apolipoprotein $\varepsilon 4$ allele: a collaborative study from the Swedish Brain Power initiative. Neurobiol Aging. 2012;33(5):1007.

64. Cadar D, Stephan BCM, Jagger C, et al. Is education a demographic dividend? The role of cognitive reserve in dementia-related cognitive decline: a comparison of six longitudinal studies of ageing. Lancet. 2015;386:S25

65. Gómez MG, Peña J. Older adults. A socioeducational study in ciudad juárez chihuaca, Mexico. Rev Interamer Educ Adultos. 2013;35(2):64-90.

66. Jenkins L, Myerson J, Joerding $\mathrm{J}$, et al. Converging evidence that visuospatial cognition is more age-sensitive than verbal cognition. Psychol Aging. 2000;15(1):157-175.

67. Luo L, Craik F. Aging and memory: a cognitive approach. Can J Psychiatry. 2008;53(6):346-353.

68. Head D, Rodrigue K, Kennedy K, et al. Neuroanatomical and cognitive mediators of agerelated differences in episodic memory. Neuropsychol. 2008;22(4):491-507.

69. Bäckman L, Small B, Fratiglioni L. Stability of the preclinical episodic memory deficit in Alzheimer's disease. Brain. 2001;124(pt 1):96-102.

70. Bäckman L, Jones S, Berger A, et al. Cognitive impairment in preclinical Alzheimer's disease: A meta-analysis. Neuropsychol. 2005;19(4):520-531.

71. Bondy M, Jak A, Delano Wood L, et al. Neuropsychological contributions to the early identification of Alzheimer's disease. Neuropsychol Rev. 2008;18(1):73-90. 